\title{
Implementasi Lean Sigma untuk Menciptakan Lingkungan Kerja Bebas Insiden di Dept. Treat \& Ship PT. CPI Duri - Riau
}

\author{
Zayyinul Hayati Zen, Akmal Nisfadilla \\ Program Studi Teknik Industri, Fakultas Teknik \\ Universitas Muhammadiyah Riau \\ Jl. Tuanku Tambusai Ujung (samping Mall SKA), Pekanbaru \\ e-mail : eza_ab@yahoo.com
}

\begin{abstract}
In effort to build incident free operations at workplaces of Treat \& Ship Department PT.Chevron Pacific Indonesia-Duri Riau, Leadership Team had to perform several efforts in many aspects. In order to focus those efforts which were performed by Leadership Team to build incident free operations at workplaces, Lean Sigma method was implemented to deliver several recommendations capturing all aspects to be focused by Leadership Team which need to be implemented to achieve better performance in Health, Environment, and Safety in order to build incident free operations at workplaces. On 20132014, there were 165 Nearmiss occurrences or 83 Nearmiss occurrences per year which those Nearmisses occurrences would potential to create incidents, such as: day away from work, injury, motor vehicle crash, oil spill, and fire. In this research identified root causes of Nearmiss occurences which potential to create incident, root causes identification done based on "procedure and safe work practices" and "design" category by using "Fishbone" method. Systematic recommendations were obtained to focus Leadership Team efforts in order to build incident free operations at workplaces, which those recommendations consist of 18 solutions. By implementing the systematic solutions recommended to Leadership Team in order to reduce and eliminate Nearmiss occurrences also to build incident free operations at workplaces in Treat \& Ship Department of PT.Chevron Pacific Indonesia-Duri Riau, it had obtained improvement results in Nearmiss occurrences which these achievements should be maintained and improved. The improvement results were Nearmiss occurrences decreased 98\% from 83 Nearmiss occurrences per year on 2013-2014 became 2 Nearmiss occurrences per year on 2015 in Treat \& Ship Department of PT.Chevron Pacific Indonesia-Duri Riau with financial benefit as much Rp.688,000,000 per year.
\end{abstract}

Keywords : Incident, Lean Sigma, and Nearmiss.

\section{Pendahuluan}

\subsection{Latar Belakang}

Memasuki perkembangan era industrialisasi yang bersifat global seperti sekarang ini, persaingan industri untuk memperebutkan pasar baik pasar tingkat regional, nasional maupun internasional, dilakukan oleh setiap perusahaan secara kompetitif. Industrialisasi tidak terlepas dari sumber daya manusia dan lingkungan kerja, yang dimana sumber daya manusia dan lingkungan kerja diharapkan dapat menjadi sumber daya yang siap pakai dan mampu membantu tercapainya tujuan perusahaan dalam bidang yang dibutuhkan. Pada dasarnya kekuatan yang ada dalam suatu perusahaan terletak pada orang-orang yang ada dalam perusahaan tersebut (Luce Neni, 2005). Apabila tenaga kerja dan lingkungan kerja diperlakukan secara tepat dan sesuai dengan harkat dan martabatnya, perusahaan akan mencapai hasil yang sesuai dengan tujuan yang diinginkan oleh perusahaan. Dari uraian tersebut jelaslah bahwa faktor Kesehatan, Lingkungan, dan Keselamatan Kerja memegang peranan yang paling penting dan utama dalam proses produksi, karena alat produksi tidak akan berjalan tanpa adanya jaminan terhadap Kesehatan, Lingkungan, dan Keselamatan Kerja.

PT. Chevron Pacific Indonesia merupakan perusahaan produsen minyak terkemuka di Indonesia dimana operasinya tersebar di seluruh Indonesia. Salah satu departemen yang ada di PT.Chevron Pacific Indonesia adalah 
Departemen Treat \& Ship yang merupakan pusat pengolahan air dan minyak yang terproduksi dari sumur-sumur produksi yang beroperasi di Duri - Riau.

Dua tahun terakhir (2013-2014) kejadian Nyaris Celaka (Nearmiss) yang berulang terjadi dimana kejadian Nyaris Celaka (Nearmiss) tersebut berpotensi mengakibatkan insiden, seperti: hari tanpa kerja, luka/celaka, kecelakaan kenderaan, tumpahan minyak, dan kebakaran. Apabila terjadi insiden di suatu operasi maka sangat banyak menimbulkan kerugian finansial yang dialami baik dari pekerja, asset/properti, lingkungan, dan lain-lain.

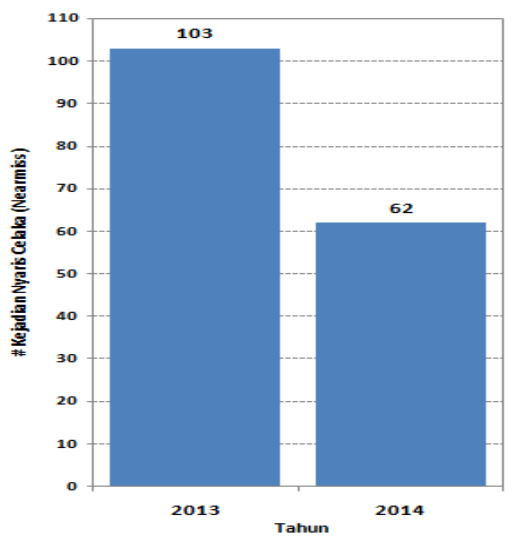

Gambar 1. Data Kejadian Nearmiss Periode2013-2014

Dari angka kejadian Nyaris Celaka (Nearmiss) yang tertera pada grafik di atas terlihat bahwa sebenarnya masih ada peluang untuk berupaya mengurangi angka kejadian Nyaris Celaka (Nearmiss) tersebut guna menghindari terjadinya insiden di lingkungan kerja.

Berdasarkan Piramida Insiden (Incident Pyramid), suatu insiden itu terjadi karena diawali dengan adanya "Tindakan dan Kondisi yang Tidak Selamat" di tempat kerja.

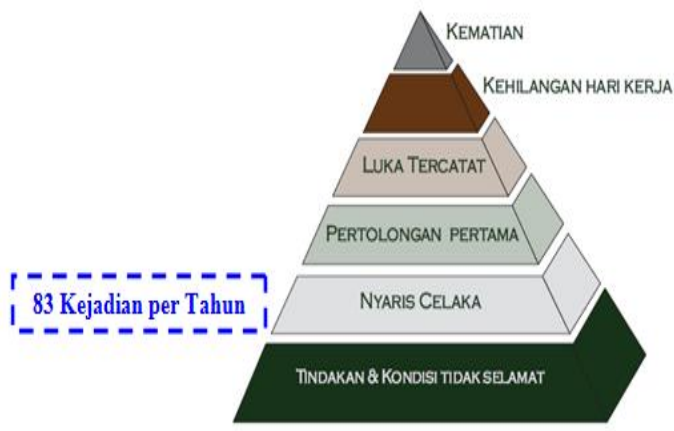

Gambar 2 Piramida Insiden (Incident Pyramid)

Perbaikan (improvement) akan menciptakan suatu budaya yang yakin akan kondisi operasioperasi yang bebas insiden (incident free operations) adalah dapat dicapai dengan bersikeras dan bersemangat untuk mencapainya. Menciptakan suatu lingkungan kerja yang selamat dan merangkul setiap pekerja agar dapat bekerja dengan selamat setiap hari, dimana setiap pekerja akan menunjukan komitmen untuk mencegah terjadinya kecelakaan, kerusakan lingkungan, dan kerusakan pada asset/properti perusahaan.

Maka dari itu perlu dilakukan penelitian tentang bagaimana memfokuskan upaya para Pimpinan dalam menciptakan lingkungan kerja yang bebas insiden (incident free operations) dan dengan adanya hubungan keakraban yang baik antara Pimpinan dengan bawahan akan membuat kesinergian yang searah sehingga tujuan bersama dalam menciptakan lingkungan kerja yang bebas insiden (incident free operations) akan lebih mudah dicapai.

\subsection{Tinjauan Pustaka}

\section{A. Kesehatan, Lingkungan, dan Keselamatan Kerja \\ Kesehatan, Lingkungan, dan Keselamatan} Kerja adalah membuat kondisi kerja yang aman dengan dilengkapi alat-alat pengaman, penerangan yang baik, menjaga lantai dan tangga bebas dari air, minyak, nyamuk dan memelihara fasilitas air yang baik (Tulus Agus, 1989).

Kesehatan, Lingkungan, dan Keselamatan Kerja bertalian dengan kecelakaan kerja, yaitu kecelakaan yang terjadi di tempat kerja atau dikenal dengan istilah kecelakaan industri (Husni, 2005). Kecelakaan industri ini secara umum dapat diartikan sebagai suatu kejadian yang tidak diduga semula dan tidak dikehendaki yang mengacaukan proses yang telah diatur dari suatu aktivitas.

\section{B. Konsep Lean Sigma dan SixSigma}

Lean Sigma dan Six Sigma adalah suatu metodologi yang terstruktur yang fokus kepada perbaikan proses (process improvement) yang diterapkan melalui proyek-proyek perbaikan proses (process improvement projects). Metodologi ini bertujuan untuk menciptakan bisnis yang lebih selamat (safer), lebih baik (better), lebih cepat (faster), dan lebih hemat biaya (lower cost).

Penerapan metodologi Lean Sigma dilakukan dengan menghilangkan proses-proses yang tidak bermanfaat (non added value processes) dan juga menyederhanakan suatu proses (process simplification) pada suatu proses operasi, yang meliputi: produk cacat (defect/rework), produksi berlebihan (over production), menunggu (waiting/delay), tidak memperdayakan SDM dengan baik (not using 
people well), transportasi (transportation), inventori (inventory), gerakan berlebih (motion in excess), proses berlebihan (excess processing).

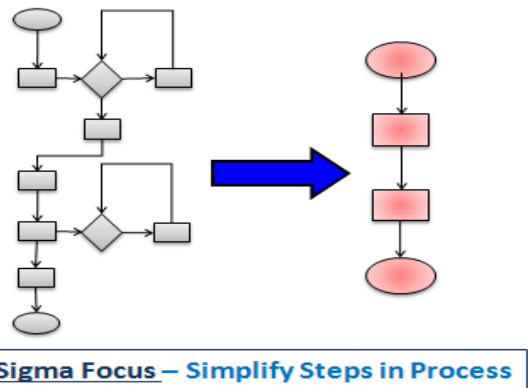

Gambar 3. Metodologi Lean Sigma

Sumber: Variance Reduction International Inc

Tahapan-tahapan dalam penerapan metodologi Lean Sigma dan Six Sigma pada suatu proyek meliputi $D-M-A-I-C$.

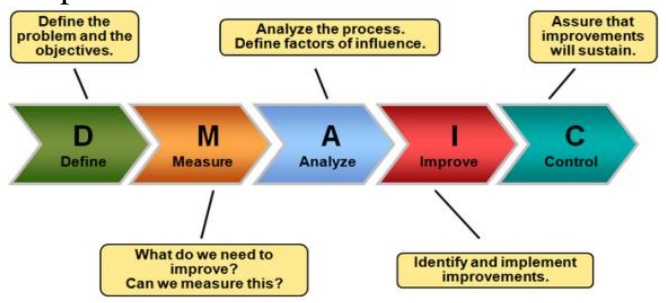

Gambar 4. Tahapan Metodologi Lean Sigma dan Six

2. Methodologi Sigma

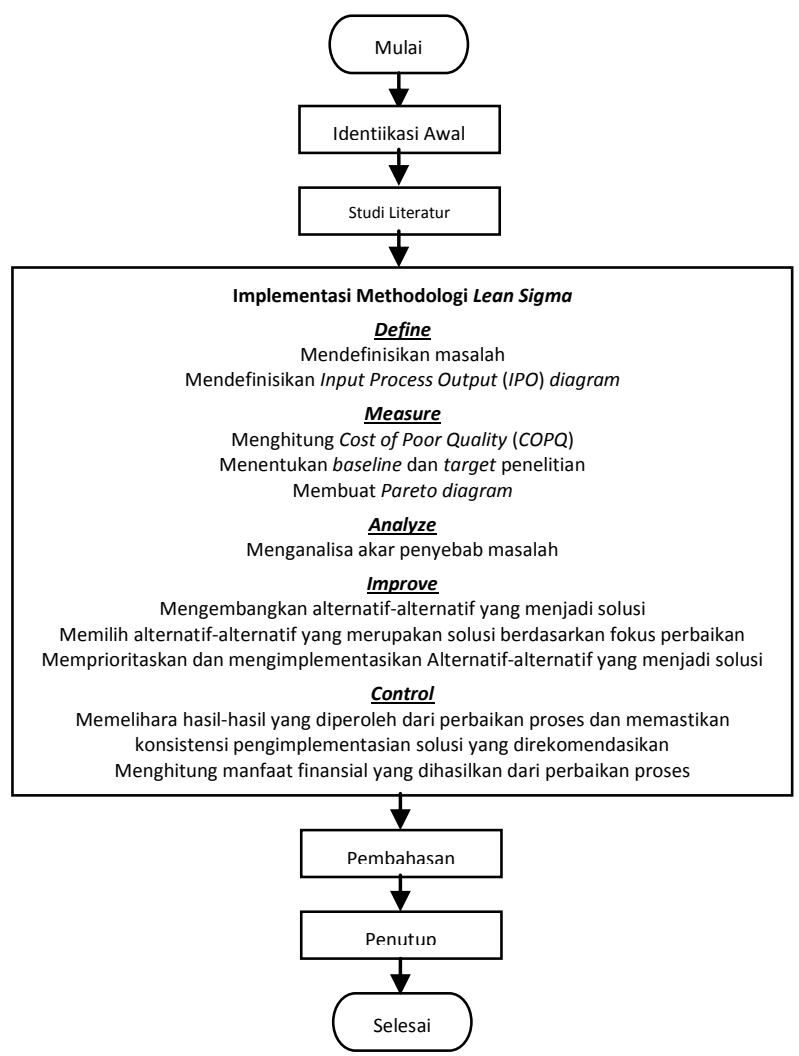

\section{Hasil dan Pembahasan}

\subsection{Tahapan Define}

\subsubsection{Mendefinisikan Masalah}

Data kejadian Nyaris Celaka (Nearmiss) yang terjadi di $C G S-01, C G S-03, C G S-04, C G S$ 05, dan CGS-10 Departemen Treat \& Ship PT.Chevron Pacific Indonesia - Duri Riau periode Tahun 2013-2014 (sebanyak 165 kejadian, atau 83 kejadian per tahun). Dan terhadap semua data kejadian Nyaris Celaka (Nearmiss) tersebut, kemudian dilakukan pengidentifikasian berdasarkan:

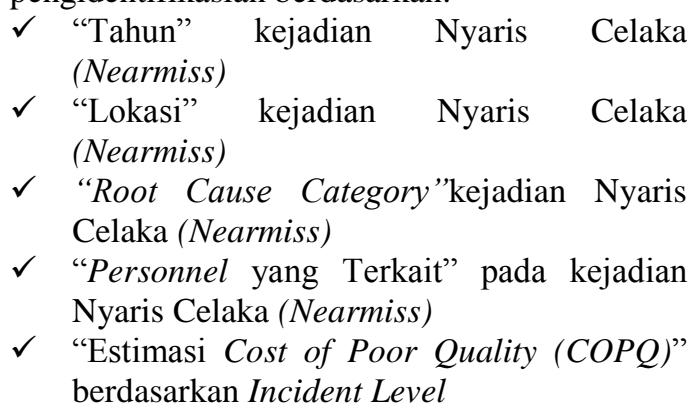

\subsubsection{Mendefinisikan Input Process Output (IPO) Diagram}

Dari deskripsi kejadian Nyaris Celaka (Nearmiss), dapat diuraikan bahwa untuk memfokuskan upaya para Pimpinan (Leadership) dalam menciptakan lingkungan kerja yang bebas insiden (incident free operations) di Departemen Treat \& Ship PT.Chevron Pacific Indonesia - Duri Riau dipengaruhi oleh faktor-faktor yang merupakan faktor-faktor Input dari metodologi Lean Sigma yang diimplementasikan pada penelitian ini sebagaimana yang terlihat dari Diagram Input Process Output (IPO Diagram) di bawah.

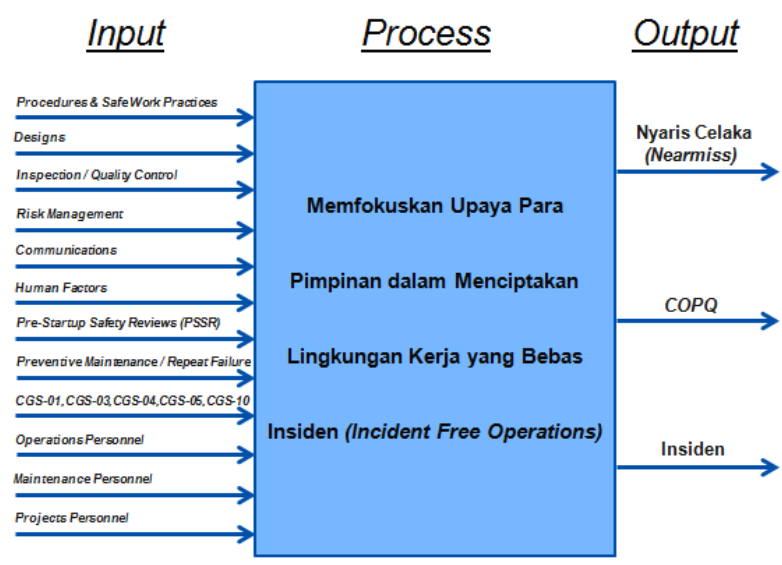

Gambar 5. Diagram Input Process Output (IPO Diagram) 


\subsection{Tahapan Measure}

3.2.1 Menghitung Cost of Poor Quality (COPQ)

Cost of Poor Quality (COPQ) ditentukan dengan mengasumsikan bahwa si pekerja benarbenar mengalami insiden yang menyebabkan luka (injury) sehingga membutuhkan biaya untuk pengobatan dan perawatan dimana besarnya biaya pengobatan dan perawatan tersebut diestimasi berdasarkan Incident Level sebagaimana pada Tabel 1:

$\checkmark$ High Incident Level, COPQ $=$

Rp.10,000,000 per insiden

$\checkmark$ Medium Incident Level, COPQ $=$

Rp.7,000,000 per insiden

$\checkmark$ Low Incident Level, COPQ $=$ Rp.4,000,000

per insiden

Estimasi besarnya Cost of Poor Quality (COPQ) untuk periode 2013-2014 adalah:

$C O P Q=$ Rp. $1,410,000,000$ per dua tahun $=$ Rp.705,000,000 per tahun

\subsubsection{Menentukan Baseline dan Target Penelitian}

Baseline dan target yang ditentukan oleh Management perusahaan pada implementasi metodologi Lean Sigma dalam penelitian ini adalah:

$\checkmark$ Mengurangi 50\% Kejadian Nyaris Celaka (Nearmiss), yaitu dari 83 Kejadaian per tahun periode 2013-2014 menjadi 42 Kejadian per tahun di 2015.

$\checkmark$ Mengurangi 50\% Cost of Poor Qiality (COPQ) dari Rp.705,000,000 per tahun menjadi Rp.352,500,000 per tahun.

$\checkmark$ Menciptakan lingkungan kerja yang bebas insiden (Incident Free Operations).

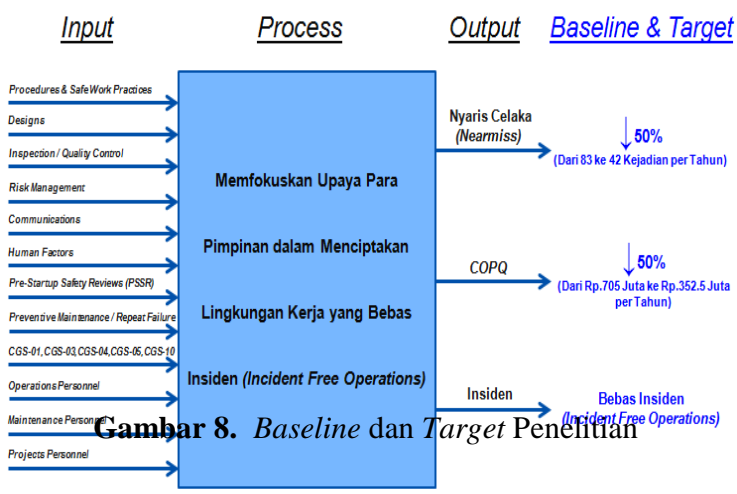

\subsubsection{Membuat PARETO Diagram}

Untuk memfokuskan faktor-faktor yang akan dilakukan perbaikan dalam implementasi metodologi Lean Sigma ini, maka seluruh data yang terkait dengan kejadian Nyaris Celaka (Nearmiss) yang diuraikan ditransformasikan ke dalam bentuk data statistik yaitu dalam bentuk PARETO Diagram.

Berikut ini PARETO Diagram untuk Kejadian Nyaris Celaka (Nearmiss) yang terjadi di periode Tahun 20132014 berdasarkan:

$\checkmark$ Root Cause Category

$\checkmark$ Lokasi Kejadian

$\checkmark$ Personnel yang Terkait dengan Kejadian

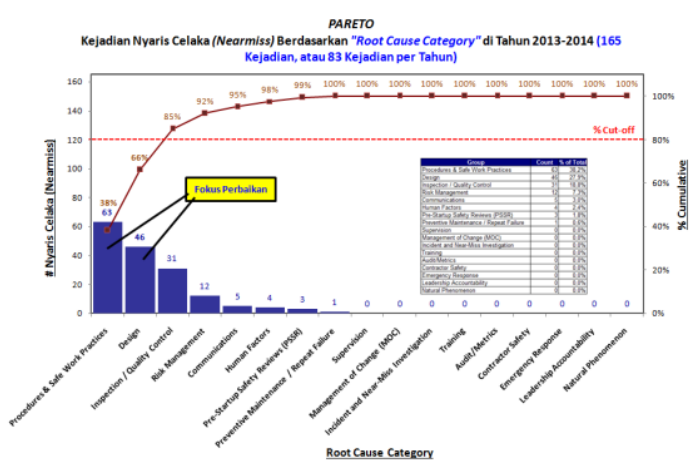

Gambar 8. PARETO Diagram Nearmiss Berdasarkan "Root Cause Category",

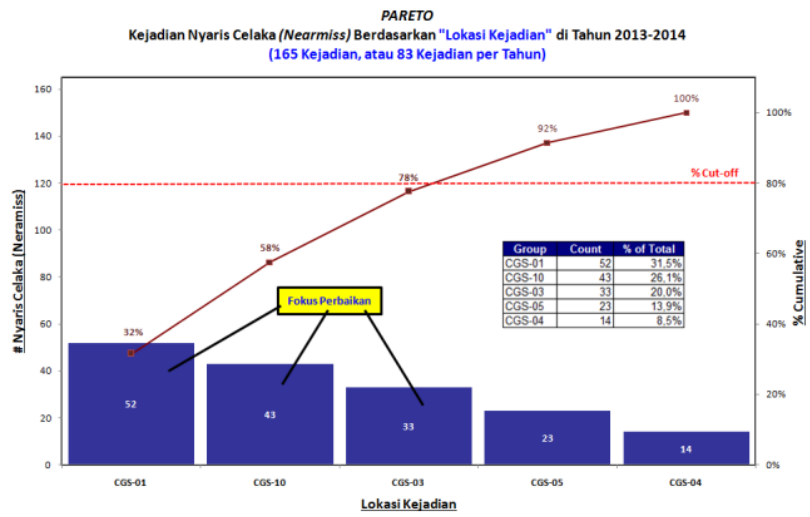

Gambar 9. PARETO Diagram Nearmiss Berdasarkan Lokasi Kejadian

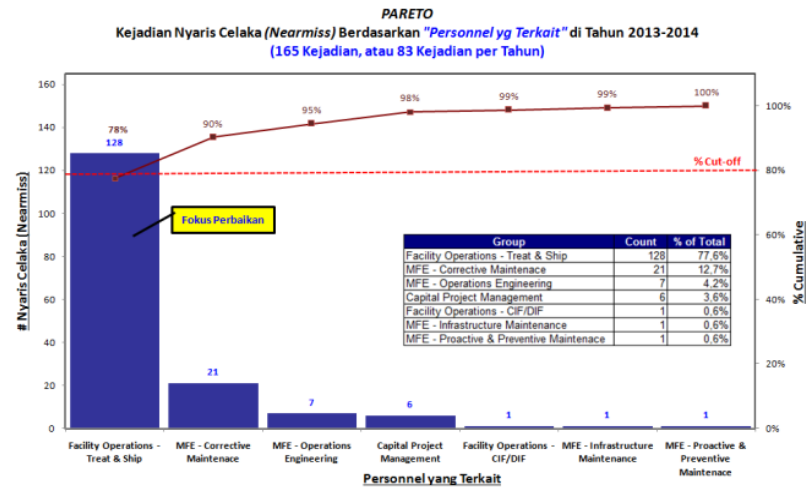

Gambar 10. PARETO Diagram Nearmiss Berdasarkan Personnel yang Terkait 
Berdasarkan PARETO Diagram pada Gambar 9, maka dilakukan fokus perbaikan kepada 2 (dua) faktor "Root Cause Category", kedua faktor tersebut adalah : Procedures and Safe Work Practices dan Design

Berdasarkan PARETO Diagram pada Gambar 10. maka dilakukan fokus perbaikan kepada 3 (tiga) faktor "Lokasi Kejadian", ketiga faktor tersebut adalah: CGS-01 Plant, CGS-10 Plant, dan CGS-03 Plant

Berdasarkan PARETO Diagram pada Gambar 11 maka dilakukan fokus perbaikan kepada 1 (satu) faktor "Personnel yang Terkait", faktor tersebut adalah: Operations Personnel.

\subsection{Tahapan Analyze}

\subsubsection{Menganalisa Akar Penyebab Masalah}

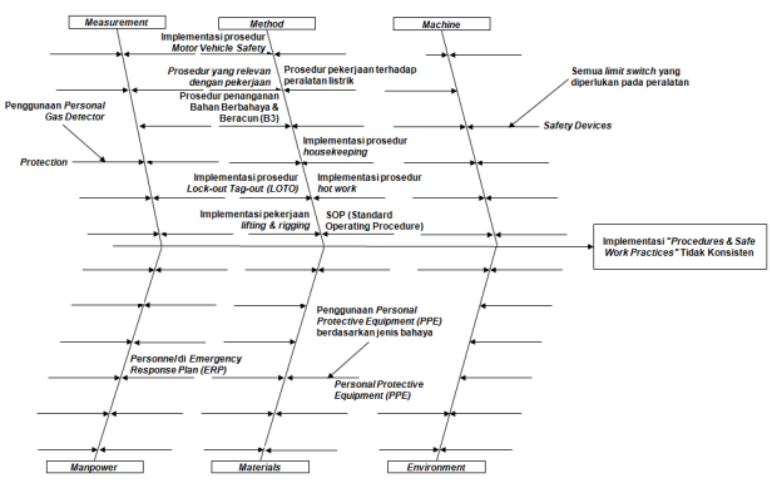

Gambar 12. Cause and Effect Diagram (Fishbone-1)

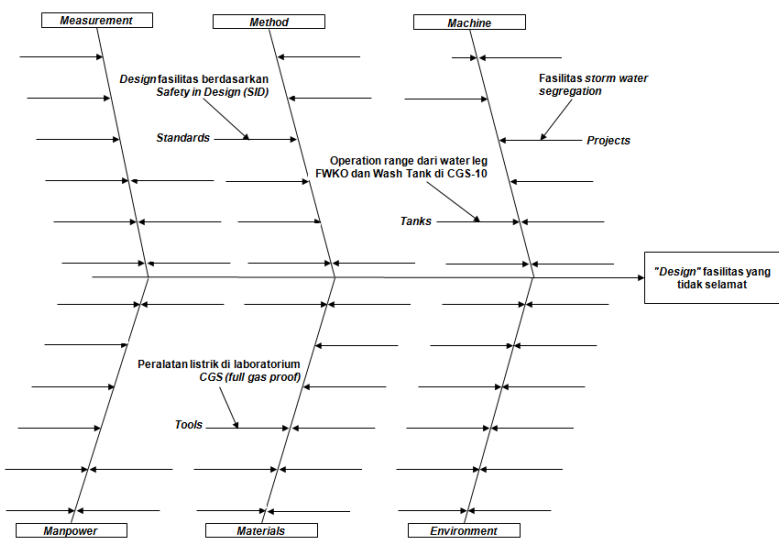

Gambar 13. Cause and Effect Diagram (Fishbone-2)

\subsection{Tahapan Improve}

\subsubsection{Mengembangkan Alternatif-alternatif yang Menjadi Solusi}

Tabel 1.

Alternatif-alternatif Solusi / Rekomendasi

\begin{tabular}{cl}
\hline NO & $\begin{array}{c}\text { ALTERNATIF-ALTERNATIF SOLUSI } \\
\text { / REKOMENDASI }\end{array}$ \\
\hline Procedures and Safe Work Practices: \\
\hline 1 & $\begin{array}{l}\text { Memastikan setiap nama personel di } \\
\text { Emergency Response Plan (ERP) harus }\end{array}$ \\
& $\begin{array}{l}\text { selalu update. } \\
\text { Memastikan konsistensi implementasi } \\
\text { prosedur Lock-Out \& Tag-Out (LOTO) } \\
\text { untuk setiap pekerjaan pada peralatan }\end{array}$ \\
3 & $\begin{array}{l}\text { Mang mengandung energi yang berbahaya. } \\
\text { proseduran konsistensi implementasi } \\
\text { pekerjaan. Housekeeping untuk setiap }\end{array}$ \\
& Memastikan
\end{tabular}

4 Memastikan konsistensi kepatuhan prosedure pekerjaan terhadap peralatan listrik di MCC berdasarkan Hazard Risk Category (HRC).

5 Memastikan langkah-langkah yang tercantum di dalam prosedur kerja (SOP) dinyatakan secara detail dan berurutan agar langkah-langkah kerja dapat dilakukan oleh setiap pekerja.

6 Memastikan setiap pekerja yang memasuki fasilitas CGS selalu mematuhi prosedur dalam hal penggunaan personel gas detector, dan memastikan personel gas detector dalam keadaan berfungsi dan dikalibrasi.

7 Memastikan konsistensi implementasi prosedur Motor Vehicle Safety (MVS) kepada setiap pengemudi kenderaan bermotor.

8 Memastikan konsistensi implementasi penggunaan Personal Protective Equipment (PPE) berdasarkan jenis bahaya yang ada di tempat kerja.

9 Memastikan konsistensi implementasi prosedur dalam penanganan Bahan Berbahaya \& Beracun (B3).

10 Memastikan setiap pekerjaan lifting dan rigging selalu dilengkapi dengan prosedur kerja dan perencanaan yang relevan dengan pekerjaan, dan selalu diawasi oleh pengawas yang bersertifikat dalam lifting dan rigging.

11 Memastikan setiap pekerjaan selalu dilengkapi dengan prosedur kerja yang relevan dengan pekerjaan dan Job Safety Analysis (JSA) yang mengidentifikasi serta memitigasi bahaya yang ada di tempat kerja, dan selalu diawasi oleh pengawas yang berkompeten.

12 Memastikan semua limit switch yang diperlukan pada peralatan selalu terpasang dan berfungsi.

13 Memastikan setiap pekerjaan Hot Work selalu dilengkapi dengan prosedur kerja yang relevan dengan pekerjaan, dan selalu diawasi oleh pengawas yang berkompeten. 


\begin{tabular}{cc}
\hline \multirow{2}{*}{ NO } & ALTERNATIF-ALTERNATIF SOLUSI \\
& $/$ REKOMENDASI \\
\hline
\end{tabular}

Design:

14 Dilakukan Engineering Review terhadap design AWT, dibuat project untuk storm water segregation di AWT.

15 Dilakukan Engineering Review terhadap operation range dari water leg di FWKO dan Wash Tanks CGS10.

16 Dilakukan Engineering Review terhadap peralatan listrik yang digunakan di laboratorium CGS, apakah peralatan listrik yang digunakan harus full gas proof.

17 Memastikan konsistensi design fasilitas memenuhi Safety in Design (SID).

18 Mempercepat penyelesaian project untuk storm water segregation di CGS.

\section{Inspection / Quality Control: \\ 19 Memastikan konsistensi implementasi Operator Routine Duty Checklist (ORDC). \\ 20 Memastikan konsistensi implementasi Regular Emergency Response Equipment Inspection. \\ 21 Memastikan konsistensi implementasi Regular Facility Inventory \& Inspection. \\ 22 Memastikan konsistensi implementasi regular Pipe Inspection pada setiap perpipaan yang berfungsi kritikal. \\ 23 Memastikan konsistensi implementasi Repair Quality Inspection pada setiap perbaikan peralatan. \\ 24 Memastikan konsistensi implementasi Vehicle Pre-trip Inspection dan Journey Managment Plan sebelum memulai perjalanan dengan menggunakan kenderaan.}

\section{Risk Management:}

25 Memastikan konsistensi penggunaan peralatan sesuai degan peruntukannya.

26 Memastikan sistem drainase dan lighting di seluruh fasilitas tersedia dan berfungsi dengan baik.

\begin{tabular}{cc}
\hline NO & ALTERNATIF-ALTERNATIF SOLUSI \\
& / REKOMENDASI \\
\hline
\end{tabular}

Communications:

27 Memastikan konsistensi implementasi protokol komunikasi yang selalu melibatkan orang yang tepat pada pekerjaan yang tidak biasa dan beresiko tinggi.

\section{Human Factors:}

28 Mensosialisasikan setiap kejadian "Nyaris Celaka (Nearmiss)" kepada setiap pekerja yang terlibat, agar kejadian yang sama tidak terulang kembali.

Pre-Startup Safety Reviews (PSSR):

29 Memastikan konsistensi implementasi Pre-Startup Safety Reviews (PSSR) untuk setiap fasilitas yang baru.

Preventive Maintenance / Repeat Failure:

30 Memastikan konsistensi implementasi regular Preventive Maintenance terhadap setiap fasilitas.

\subsubsection{Memilih Alternatif-alternatif yang Merupakan Solusi/ Rekomendasi Berdasarkan Fokus Perbaikan}

Tabel 2.

Alternatif-alternatif Solusi / Rekomendasi yang Dipilih Berdasarkan Fokus Perbaikan

\begin{tabular}{cl}
\multicolumn{1}{c}{ Berdasarkan Fokus Perbaikan } \\
\hline NO & \multicolumn{1}{c}{ SOLUSI / REKOMENDASI YANG } \\
DIPILIH
\end{tabular}




\begin{tabular}{|c|c|}
\hline $\mathrm{NO}$ & $\begin{array}{l}\text { SOLUSI / REKOMENDASI YANG } \\
\text { DIPILIH } \\
\end{array}$ \\
\hline 6 & $\begin{array}{l}\text { dapat dilakukan oleh setiap pekerja. } \\
\text { Memastikan setiap pekerja yang } \\
\text { memasuki fasilitas CGS selalu } \\
\text { mematuhi prosedur dalam hal } \\
\text { penggunaan personel gas detector, } \\
\text { dan memastikan personel gas detector } \\
\text { dalam keadaan berfungsi dan } \\
\text { dikalibrasi. }\end{array}$ \\
\hline 7 & $\begin{array}{l}\text { Memastikan } \\
\text { implementasi prosedur Motor } \\
\text { Vehicle Safety (MVS) kepada setiap } \\
\text { pengemudi kenderaan bermotor. }\end{array}$ \\
\hline 8 & $\begin{array}{l}\text { Memastikan } \\
\text { implementasi penggunaan Personal } \\
\text { Protective Equipment } \\
\text { berdasarkan jenis bahaya yang ada di } \\
\text { tempat kerja. }\end{array}$ \\
\hline 9 & $\begin{array}{l}\text { Memastikan } \\
\text { implementasi } \\
\text { penanganan } \text { prosedur dahan Berbahaya \& }\end{array}$ \\
\hline 10 & $\begin{array}{l}\text { Beracun (B3). } \\
\text { Memastikan setiap pekerjaan lifting } \\
\text { dan rigging selalu dilengkapi dengan } \\
\text { prosedur kerja dan perencanaan yang } \\
\text { relevan dengan pekerjaan, dan selalu } \\
\text { diawasi oleh pengawas yang } \\
\text { bersertifikat dalam lifting dan } \\
\text { rigging. }\end{array}$ \\
\hline 11 & $\begin{array}{l}\text { Memastikan setiap pekerjaan selalu } \\
\text { dilengkapi dengan prosedur kerja } \\
\text { yang relevan dengan pekerjaan dan } \\
\text { Job Safety Analysis (JSA) yang } \\
\text { mengidentifikasi serta memitigasi } \\
\text { bahaya yang ada di tempat kerja, dan } \\
\text { selalu diawasi oleh pengawas yang } \\
\text { berkompeten. }\end{array}$ \\
\hline 12 & $\begin{array}{l}\text { Memastikan semua limit switch yang } \\
\text { diperlukan pada peralatan selalu } \\
\text { terpasang dan berfungsi. }\end{array}$ \\
\hline 13 & $\begin{array}{l}\text { Memastikan setiap pekerjaan Hot } \\
\text { Work selalu dilengkapi dengan } \\
\text { prosedur kerja yang relevan dengan } \\
\text { pekerjaan, dan selalu diawasi oleh } \\
\text { pengawas yang berkompeten. }\end{array}$ \\
\hline
\end{tabular}

Design:

Dilakukan Engineering Review terhadap design AWT, dibuat project untuk storm water segregation di AWT.

Dilakukan Engineering Review

15 terhadap operation range dari water leg di FWKO dan Wash Tanks CGS10.

16 Dilakukan Engineering Review

\begin{tabular}{|c|c|}
\hline $\mathrm{NO}$ & $\begin{array}{l}\text { SOLUSI / REKOMENDASI YANG } \\
\text { DIPILIH }\end{array}$ \\
\hline & $\begin{array}{lcc}\text { terhadap } & \text { peralatan listrik } & \text { yang } \\
\text { digunakan di laboratorium } & \text { CGS, } \\
\text { apakah peralatan listrik } & \text { yang } \\
\text { digunakan harus full gas proof. } & \end{array}$ \\
\hline 17 & $\begin{array}{l}\text { Memastikan konsistensi design } \\
\text { fasilitas memenuhi Safety in Design } \\
\text { (SID). }\end{array}$ \\
\hline 18 & $\begin{array}{l}\text { Mempercepat penyelesaian project } \\
\text { untuk storm water segregation di } \\
\text { CGS. }\end{array}$ \\
\hline
\end{tabular}

\subsubsection{Memprioritaskan dan \\ Mengimplementasikan Alternatif-alternatif yang Menjadi Solusi/ Rekomendasi}

Tabel 3.

Urutan Prioritas Solusi / Rekomendasi Berdasarkan Tingkatan Resikonya (Risk Classification)

\begin{tabular}{|c|c|c|c|c|}
\hline $\begin{array}{l}\mathbf{N} \\
\mathbf{O}\end{array}$ & $\begin{array}{c}\text { SOLUSI / } \\
\text { REKOMENDASI }\end{array}$ & $C$ & $L$ & $\boldsymbol{R C}$ \\
\hline 1 & $\begin{array}{l}\text { Memastikan konsistensi } \\
\text { implementasi prosedur Lock- } \\
\text { Out \& Tag-Out (LOTO) } \\
\text { untuk setiap pekerjaan pada } \\
\text { peralatan yang mengandung } \\
\text { energi yang berbahaya. }\end{array}$ & 1 & 1 & 1 \\
\hline 2 & $\begin{array}{l}\text { Memastikan } \\
\text { kepatuhan } \\
\text { pekerjaan terhadap peralatan } \\
\text { listrik di } \\
\text { Hazard } \\
\text { Hazensi } \\
\text { (HRC). }\end{array}$ & 1 & 1 & 1 \\
\hline 3 & \begin{tabular}{lrr}
\multicolumn{3}{l}{ Memastikan langkah-langkah } \\
yang tercantum di & dalam \\
prosedur & kerja & (SOP) \\
dinyatakan & secara & detail dan \\
berurutan & agar & langkah- \\
langkah & kerja & dapat \\
dilakukan & oleh & setiap \\
pekerja. & &
\end{tabular} & 1 & 1 & 1 \\
\hline 4 & $\begin{array}{l}\text { Memastikan setiap pekerja } \\
\text { yang memasuki fasilitas CGS } \\
\text { selalu mematuhi prosedur } \\
\text { dalam hal penggunaan } \\
\text { personel gas detector, dan } \\
\text { memastikan personel gas } \\
\text { detector dalam keadaan } \\
\text { berfungsi dan dikalibrasi. }\end{array}$ & 1 & 1 & 1 \\
\hline 5 & $\begin{array}{l}\text { Memastikan konsistensi } \\
\text { implementasi prosedur Motor } \\
\text { Vehicle Safety (MVS) } \\
\text { kepada setiap pengemudi } \\
\text { kenderaan bermotor. }\end{array}$ & 1 & 1 & 1 \\
\hline 6 & $\begin{array}{lr}\text { Memastikan } & \text { konsistensi } \\
\text { implementasi } & \text { penggunaan } \\
\text { Personal } & \text { Protective } \\
\text { Equipment } & \text { (PPE) } \\
\text { berdasarkan jenis bahaya } \\
\text { yang ada di tempat kerja. }\end{array}$ & 1 & 1 & 1 \\
\hline 7 & $\begin{array}{l}\text { Memastikan setiap pekerjaan } \\
\text { selalu dilengkapi dengan } \\
\text { prosedur kerja yang relevan } \\
\text { dengan pekerjaan dan Job }\end{array}$ & 1 & 1 & 1 \\
\hline
\end{tabular}




\begin{tabular}{|c|c|c|c|c|}
\hline $\begin{array}{l}\mathbf{N} \\
\mathbf{O}\end{array}$ & $\begin{array}{c}\text { SOLUSI / } \\
\text { REKOMENDASI }\end{array}$ & $C$ & $L$ & $R C$ \\
\hline & $\begin{array}{l}\text { Safety Analysis (JSA) yang } \\
\text { mengidentifikasi } \quad \text { serta } \\
\text { memitigasi bahaya yang ada } \\
\text { di tempat kerja, dan selalu } \\
\text { diawasi oleh pengawas yang }\end{array}$ & & & \\
\hline 8 & $\begin{array}{l}\text { Memastikan } \\
\text { implementasi }\end{array}$ & 2 & 1 & 2 \\
\hline 9 & $\begin{array}{lr}\text { Memastikan } & \text { konsistensi } \\
\text { implementasi prosedur dalam } \\
\text { penanganan }\end{array}$ & 1 & 2 & 2 \\
\hline & $\begin{array}{l}\text { Berbahaya \& Beracun (B3). } \\
\text { Memastikan setiap pekerjaan } \\
\text { lifting dan rigging selalu } \\
\text { dilengkapi dengan prosedur }\end{array}$ & & & \\
\hline 10 & $\begin{array}{l}\text { kerja dan perencanaan yang } \\
\text { relevan dengan pekerjaan, } \\
\text { dan selalu diawasi oleh } \\
\text { pengawas yang bersertifikat } \\
\text { dalam lifting dan rigging. }\end{array}$ & 1 & 2 & 2 \\
\hline & Memastikan setiap pekerjaan & & & \\
\hline 11 & $\begin{array}{l}\text { Hot Work selalu dilengkapi } \\
\text { dengan prosedur kerja yang } \\
\text { relevan dengan pekerjaan, } \\
\text { dan selalu diawasi oleh } \\
\text { pengawas yang berkompeten. }\end{array}$ & 1 & 2 & 2 \\
\hline 12 & $\begin{array}{l}\text { Memastikan konsistensi } \\
\text { design fasilitas memenuhi } \\
\text { Safety in Design (SID). }\end{array}$ & 1 & 2 & 2 \\
\hline 13 & $\begin{array}{l}\text { Memastikan semua limit } \\
\text { switch yang diperlukan pada } \\
\text { peralatan selalu terpasang } \\
\text { dan berfungsi. }\end{array}$ & 1 & 3 & 3 \\
\hline & $\begin{array}{l}\text { Dilakukan } \begin{array}{r}\text { Engineering } \\
\text { Review terhadap design }\end{array}\end{array}$ & & & \\
\hline 14 & $\begin{array}{l}\text { AWT, dibuat project untuk } \\
\text { storm water segregation di } \\
\text { AWT. }\end{array}$ & 2 & 2 & 3 \\
\hline & Engineering & & & \\
\hline 15 & $\begin{array}{l}\text { Review terhadap peralatan } \\
\text { listrik yang digunakan di } \\
\text { laboratorium CGS, apakah } \\
\text { peralatan listrik yang } \\
\text { digunakan harus full gas } \\
\text { proof. }\end{array}$ & 1 & 3 & 3 \\
\hline 16 & $\begin{array}{l}\text { Mempercepat penyelesaian } \\
\text { project untuk storm water } \\
\text { segregation di CGS. }\end{array}$ & 2 & 2 & 3 \\
\hline & Dilakukan Engineering & & & \\
\hline 17 & $\begin{array}{l}\text { Review terhadap operation } \\
\text { range dari water leg di } \\
\text { FWKO dan Wash Tanks } \\
\text { CGS-10. }\end{array}$ & 2 & 3 & 4 \\
\hline 18 & $\begin{array}{l}\text { Memastikan setiap nama } \\
\text { personel di Emergency } \\
\text { Response Plan (ERP) harus } \\
\text { selalu update. }\end{array}$ & 3 & 3 & 5 \\
\hline
\end{tabular}

\subsection{Tahapan Control}

\subsubsection{Memelihara Hasil-hasil yang Diperoleh} dari Perbaikan Proses dan Memastikan Konsistensi Pengimplementasian Solusi yang Direkomendasikan
Berikut ini adalah detail deskripsi pencapaian perbaikan yang diperoleh terhadap angka kejadian Nyaris Celaka (Nearmiss) di Tahun 2015 yang ditunjukkan berdasarkan: "Root Cause Category", "Lokasi Kejadian", dan "Personnel yang Terkait" dengan kejadian yang terjadi di Departemen Treat \& Ship PT.Chevron Pacific Indonesia-Duri Riau periode Tahun 2015.

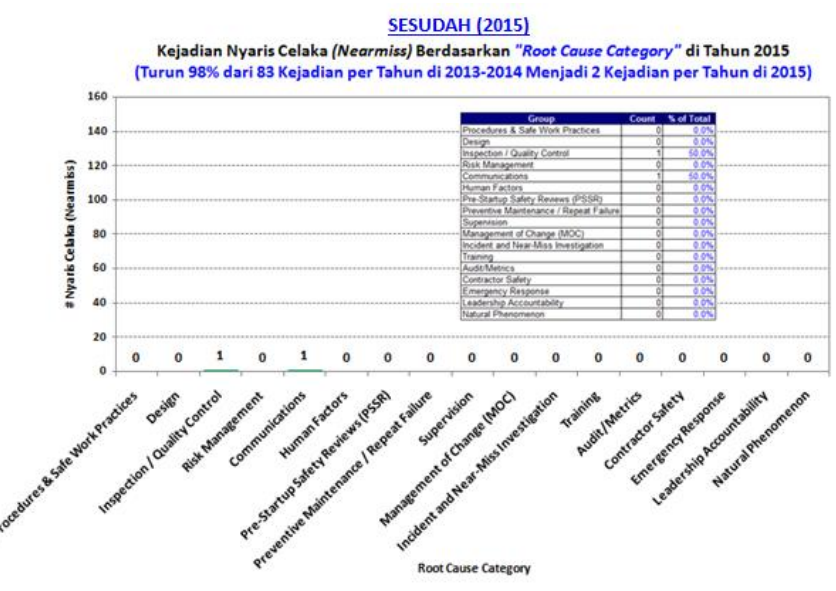

Gambar 14. Diagram Nearmiss Berdasarkan "Root Cause Category" 2015

Dari diagram di atas bahwa berdasarkan Root Cause Category, 2 (dua) Kejadian Nyaris Celaka (Nearmiss) di Tahun 2015 terjadi pada kategori: "Inspection/ Quality Control" dan "Communications" dimana kedua kategori kejadian Nyaris Celaka (Nearmiss) tersebut merupakan faktor yang belum menjadi fokus pada perbaikan di Tahapan Improve karena pada PARETO Diagram (Gambar 10), kedua Root Cause Category tersebut tidak menjadi fokus untuk diperbaiki.

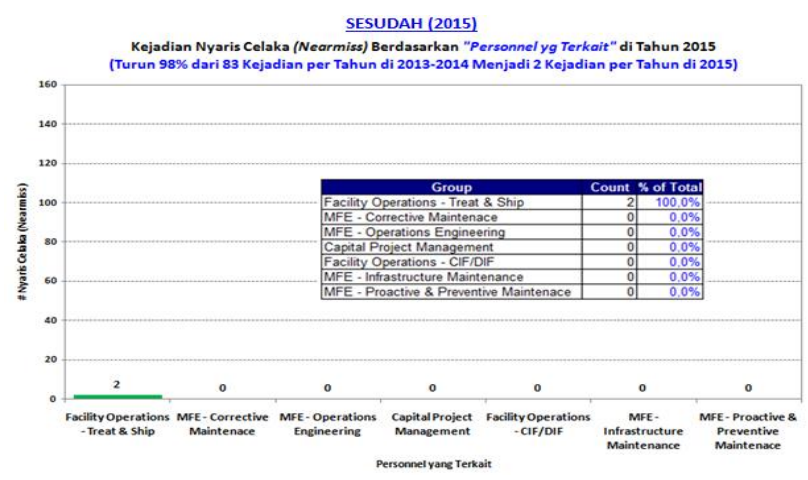

Gambar 15. Diagram Nearmiss Berdasarkan "Lokasi Kejadian" 2015

Dari diagram di atas bahwa berdasarkan Lokasi Kejadian, 2 (dua) Kejadian Nyaris 
Celaka (Nearmiss) di Tahun 2015 terjadi di lokasi: "CGS-01 Plant" dan "CGS-03 Plant" dimana kedua Lokasi Kejadian Nyaris Celaka (Nearmiss) tersebut merupakan faktor yang termasuk difokuskan pada solusi yang direkomendasikan kepada para Pimpinan (Leadership) pada saat Tahapan Improve karena pada PARETO Diagram (Gambar 11) kedua Lokasi Kejadian tersebut menjadi fokus perbaikan, namun angka kejadian Nyaris Celaka (Nearmiss) di Tahun 2015 (sampai dengan penelitian dilakukan) ini sudah jauh berkurang.

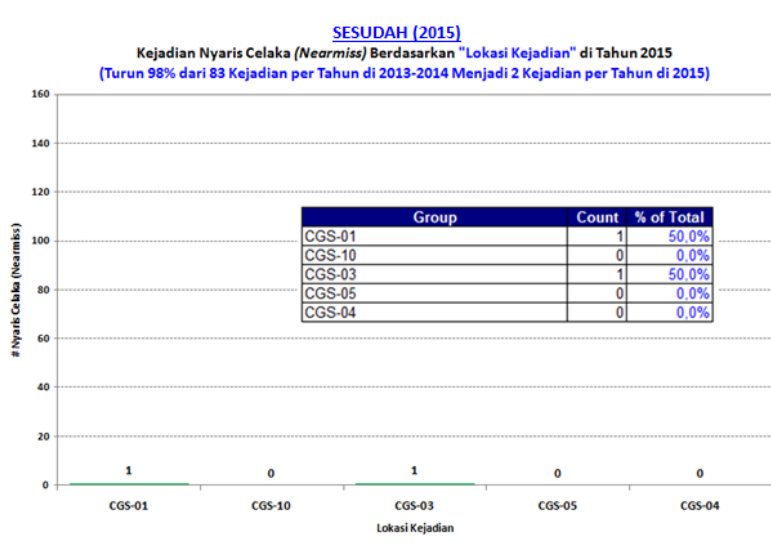

Gambar 16. Diagram Nearmiss Berdasarkan "Personnel yang Terkait" 2015

Untuk memastikan konsistensi pengimplementasian solusi atau rekomendasi yang diimplementasikan oleh para Pimpinan (Leadership) dalam mengurangi dan menghilangkan angka kejadian Nyaris Celaka (Nearmiss) serta menciptakan lingkungan kerja yang bebas insiden (Incident Free Operations) di Departemen Treat \& Ship PT.Chevron Pacific Indonesia-Duri Riau, maka dilakukan Control Plan seperti pada tabel berikut.

Tabel 4.

Control Plan

\begin{tabular}{|c|c|}
\hline FUNCTION & CONTROL PLAN \\
\hline Facilitator & 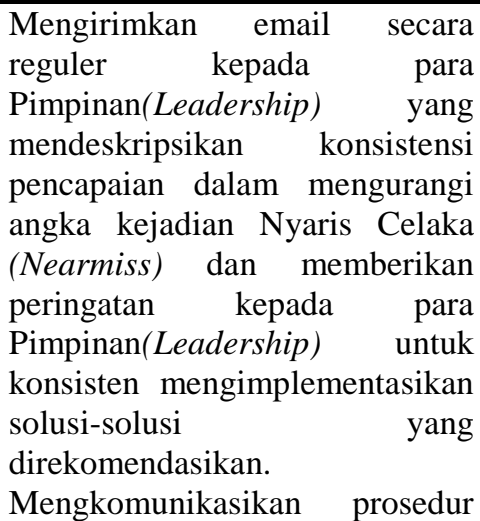 \\
\hline
\end{tabular}

\begin{tabular}{ll}
\hline FUNCTION & \multicolumn{3}{c}{ CONTROL PLAN } \\
\hline Facilitator & $\begin{array}{l}\text { protokol komunikasi pada } \\
\text { Control Phase ini kepada para }\end{array}$ \\
& $\begin{array}{l}\text { Pimpinan (Leadership) dan } \\
\text { semua pihak yang terkait dan } \\
\text { memastikan target atau tujuan } \\
\text { dari perbaikan proses ini dapat }\end{array}$ \\
& dicapai dengan sebaik-baiknya. \\
& Memastikan seluruh prosedur \\
& dan seluruh solusi atau \\
rekomendasi dilaksanakan \\
sponsor \\
sebaik-baiknya dengan konsisten \\
sebagaimana yang diharapkan.
\end{tabular}

\subsubsection{Menghitung Manfaat Finansial yang Dihasilkan dari Perbaikan Proses}

Cost of Poor Quality (COPQ) ditentukan dengan mengasumsikan bahwa si pekerja benarbenar mengalami insiden yang menyebabkan luka (injury) sehingga membutuhkan biaya untuk pengobatan dan perawatan dimana besarnya biaya pengobatan dan perawatan tersebut diestimasi berdasarkan Incident Level:

$\checkmark$ High Incident Level, COPQ $=$

Rp.10,000,000 per insiden

$\checkmark$ Medium Incident Level, COPQ $=$

Rp.7,000,000 per insiden

$\checkmark$ Low Incident Level, COPQ $=$ Rp.4,000,000

per insiden

Dari 165 kejadian Nyaris Celaka (Nearmiss) atau 83 kejadian Nyaris Celaka (Nearmiss) di Tahun 2013-2014, maka estimasi besarnya Cost of Poor Quality (COPQ) untuk periode 20132014 adalah:

$$
C O P Q=\text { Rp.1,410,000,000 per dua tahun }
$$$$
\text { = Rp.705,000,000 per tahun }
$$

Setelah dilakukan perbaikan, di Tahun 2015 terjadi hanya 2 (dua) kejadian Nyaris Celaka (Nearmiss) dengan estimasi besarnya Cost of Poor Quality (COPQ) di Tahun 2015 adalah Rp.17,000,000.

Sehingga manfaat finansial setelah dilakukan perbaikan di Tahun 2015 adalah:

Manfaat Finansial $=$ Rp.705,000,000,00 Rp. $17,000,000,00=$ Rp.688,000,000,00

\section{Simpulan}

Beberapa kesimpulan dari penelitian ini adalah sebagai berikut :

a. Akar penyebab terjadinya kejadian Nyaris Celaka (Nearmiss) berdasarkan Root Cause Category adalah "implementasi Procedures \& Safe Work Practice yang tidak konsisten" yaitu: implementasi 
penggunaan Personal Protective Equipment (PPE), implementasi prosedur Lock-Out \& Tag-Out (LOTO), implementasi prosedur Motor Vehicle Safety (MVS), kepatuhan prosedure pekerjaan terhadap peralatan listrik di $M C C$, implementasi Standard Operating Procedure (SOP) yang dinyatakan secara detail dan berurutan, verifikasi semua limit switch, verifikasi nama personnel di Emergency Response Plan (ERP) selalu update, verifikasi setiap pekerja yang memasuki fasilitas $C G S$ selalu mematuhi prosedur dalam hal penggunaan personel gas detector dan personel gas detector dalam keadaan berfungsi dan dikalibrasi, verifikasi setiap pekerjaan Hot Work selalu dilengkapi dengan prosedur kerja yang relevan dengan pekerjaan dan selalu diawasi oleh pengawas yang berkompeten, verifikasi setiap pekerjaan lifting dan rigging selalu dilengkapi dengan prosedur kerja dan perencanaan yang relevan dengan pekerjaan serta selalu diawasi oleh pengawas yang bersertifikat dalam lifting dan rigging, dan verifikasi setiap pekerjaan selalu dilengkapi dengan prosedur kerja yang relevan dengan pekerjaan dan Job Safety Analysis (JSA) yang mengidentifikasi serta memitigasi bahaya yang ada di tempat kerja serta selalu diawasi oleh pengawas yang berkompeten.

b. Upaya pimpinan (leadership) yang diimplementasikan berdasarkan tingkatan prioritasnya untuk mengurangi dan menghilangkan angka kejadian Nyaris Celaka (Nearmiss) serta menciptakan lingkungan kerja yang bebas insiden (Incident Free Operations) di Departemen Treat \& Ship PT.Chevron Pacific Indonesia-Duri Riau.

c. Dengan pengimplementasian solusi berdasarkan urutan prioritas oleh para Pimpinan (Leadership) untuk mengurangi dan menghilangkan angka kejadian Nyaris Celaka (Nearmiss) serta menciptakan lingkungan kerja yang bebas insiden (Incident Free Operations) di Departemen Treat \& Ship PT.Chevron Pacific Indonesia-Duri Riau, maka diperoleh hasil perbaikan terhadap angka kejadian Nyaris Celaka (Nearmiss) yang harus dipelihara dan ditingkatkan pencapaiannya. Hasil perbaikan yang diperoleh terhadap angka kejadian Nyaris Celaka (Nearmiss) adalah turun $98 \%$ dari 83 Kejadian Nyaris Celaka (Nearmiss) per tahun di 2013-2014 menjadi 2 Kejadian Nyaris Celaka (Nearmiss) per tahun di 2015 di Departemen Treat \& Ship
PT.Chevron Pacific Indonesia-Duri Riau dengan selisih manfaat finansial sebesar Rp. 688.000.000 per tahun.

\section{Daftar Pustaka}

[1] George, Michael L; Rowlands, David; Price, Mark; Maxey, John, 2005, The Lean Sigma and Six Sigma Pocket Toolbook, New York, United States of America.

[2] Ibrahim Jati Kusuma, 2010, Jurnal Pelaksanaan Program Keselamatan dan Kesehatan Kerja Karyawan PT.Bitratex Industries Semarang. http://eprints.undip.ac.id/26498/2/Jurnal.pdf

[3] PT.Chevron Pacific Indonesia, 2006, Fundamental Safe Work Practices, Duri, Indonesia.

[4] PT.Chevron Pacific Indonesia, 2011, IBU Fundamental Safe Work Practices Guidebook, Jakarta, Indonesia.

[5] PT.Chevron Pacific Indonesia, Skill Based Progession System, Manual-2, Duri, Indonesia.

[6] Rother, Mike; Shook, John, 2009, Learning to See Value Stream Mapping to Create Value and Eliminate Muda, Cambridge, United States of America.

[7] Universitas Muhammadiyah Riau, 2011, Buku Panduan Tugas Akhir, Pekanbaru, Indonesia.

[8] Variance Reduction International Inc, 2009, Lean Manufacturing Lean Office, Participant Guide, Bakersfield, United States of America.

[9] Variance Reduction International Inc, 2009, Six Sigma Tools for Process Improvements, Green Belt / Black Belt Participant Guide, Bakersfield, United States of America. 